Part of Journal of Research of the National Bureau of Standards, Volume 19, July 1937

\title{
DETERMINATION OF PHOSPHORIC ANHYDRIDE IN PHOSPHATE ROCK, SUPERPHOSPHATE, AND "META- PHOSPHATE"
}

\author{
By James I. Hoffman and G. E. F. Lundell
}

\section{ABSTRACT}

A gravimetric method requiring no molybdate reagent is described for the determination of phosphoric anhydride in phosphate rock and similar materials. In this method a precipitation with a large excess of magnesia mixture in the presence of ammonium citrate serves to separate the phosphate ion from the other constituents. A second precipitation yields a precipitate of definite composition which is converted to magnesium pyrophosphate, $\mathrm{Mg}_{2} \mathrm{P}_{2} \mathrm{O}_{7}$, on ignition. The method has been successfully applied to phosphate rock, superphosphate, "metaphosphate", and liquids used with silicate cements in dentistry. It is recommended for use in standardization and umpire analyses of phosphate rocks and similar materials, but it is not sufficiently rapid to replace the usual volumetric method now employed in routine analyses.

\section{CONTENTS}

Page

I. Introduction

II. Procedure

1. Preparation of the solution 60

2. Determination of phosphoric anhydride

III. Results obtained in the use of the method. 62

IV. Discussion of the method and its application

\section{INTRODUCTION}

For the accurate determination of phosphorus pentoxide in phosphate rock and similar materials, it has been customary first to precipitate the phosphate ion as yellow ammonium phosphomolybdate in order to separate it from calcium, iron, aluminum, and other constituents. ${ }^{1}$ In the usual procedure, the yellow precipitate is dissolved in ammonium hydroxide, magnesia mixture is added, and magnesium ammonium phosphate containing impurities is precipitated. The impure precipitate is dissolved in hydrochloric acid, more magnesia mixture is added, and the phosphorus is precipitated as magnesium ammonium phosphate under closely controlled conditions so that a precipitate of definite composition is obtained. This precipitate is then ignited at 1,050 to $1,100^{\circ} \mathrm{C}$, and the residue is weighed as magnesium pyrophosphate, $\mathrm{Mg}_{2} \mathrm{P}_{2} \mathrm{O}_{7}$. Slightly high and somewhat erratic results are usually obtained if only one precipitation with magnesia mixture is made.

1 See G. E. F. Lundell and J. I. Hoffman, The analysis of phosphate rock, J. Assn. Official Agr. Chem. 8, 184 (1924). 
In 1924 the authors ${ }^{2}$ observed that a relatively large amount of calcium oxide, added to the phosphate solution, did not cause any error in the determination of phosphorus pentoxide if two precipitations with magnesia mixture were made in the presence of ammonium citrate. It was also shown that under the same conditions ammonium citrate prevented the precipitation of iron and aluminum. These observations suggested the possibility of precipitating the phosphorus directly with magnesia mixture in the presence of the calcium, aluminum, iron, and other constituents of the phosphate rock, thus eliminating the usual preliminary precipitation with molybdate reagent. Numerous tests were accordingly made which showed that under proper conditions the phosphorus pentoxide in a solution of phosphate rock and similar materials can be determined by (1) precipitating directly with a large excess of magnesia mixture; (2) filtering; (3) dissolving the precipitate; (4) precipitating with the usual small excess of magnesia mixture; (5) filtering; (6) igniting the precipitate; and (7) weighing the residue as magnesium pyrophosphate. The details of this procedure are given in section II.

\section{PROCEDURE}

\section{PREPARATION OF THE SOLUTION}

Method A. (Applicable to phosphate rock and superphosphate).Transfer $2.500 \mathrm{~g}$ of the dried material to a 300-ml Erlenmeyer flask, add $30 \mathrm{ml}$ of hydrochloric acid and $10 \mathrm{ml}$ of nitric acid. Place a small watch glass over the mouth of the flask, and boil gently for $30 \mathrm{~min}-$ utes. Rinse the glass, add $50 \mathrm{ml}$ of water, heat to boiling, and filter through a paper of close texture, catching the filtrate in a $250-\mathrm{ml}$ volumetric flask. Wash the paper ${ }^{3}$ and the Erlenmeyer flask thoroughly with diluted hydrochloric acid ${ }^{4}(1+4)$, cool the contents of the volumetric flask to the proper temperature, and add water until the flask is filled to the mark. Mix thoroughly and transfer $50.00 \mathrm{ml}$ of the solution (representing $0.5000 \mathrm{~g}$ of sample) to a $300-\mathrm{ml}$ Erlenmeyer flask.

Method $B$ (Applicable to phosphate rock and superphosphate).Transfer $0.5000 \mathrm{~g}$ of the dried material to a $300-\mathrm{ml}$ Erlenmeyer flask, and add $15 \mathrm{ml}$ of hydrochloric acid and $3 \mathrm{ml}$ of nitric acid. Place a small watch glass over the mouth of the flask, and boil gently for 30 minutes. Rinse and remove the watch glass, and, without filtering, proceed with the addition of ammonium citrate, hydrochloric acid, and magnesia mixture as described in 2.

This method obviates the use of volumetric glassware and requires less time than method $A$. The results obtained are equally accurate if the material contains no appreciable amount of insoluble compounds of phosphorus.

\footnotetext{
2 J. Assn. Official Agr. Chem. 8, 188 (1924).

3 By applying the treatment prescribed, no phosphorusis volatilized, and only 0.03 percent of $\mathrm{P}_{2} \mathrm{O}_{5}$ remains in the insoluble residue in the case of the National Bureau of Standards Sample 56, and less than 0.005 percent in Samples 56a and 120 . Unless it is known that no phosphorus remains insoluble, ignite the paper and insoluble residue in platinum, fuse with a small quantity of sodium carbonate, and leach the cooled melt with hot water. Filter, acidify the filtrate with hydrochloric acid, and add the solution to the contents of the volumetric flask. Or alternatively, if the filtrate is acidified with nitric acid, the phosphorus may be precipitated with molybdate reagent, separately determined, and the percentage found added to that obtained in the main determination.

This denotes 1 volume of concentrated hydrochloric acid ( $\mathrm{sp}$ gr 1.18) diluted with 4 volumes of water. This denotes 1 volume of concentrated hydrochloric acid (sp gr 1.18) diluted with 4 volumes of water.
Diluted ammonium hydroxide $(1+19)$ denotes 1 volume of ammonium hydroxide (sp gr 0.90) diluted with 19 volumes of water. If no dilution is specified, the concentrated reagent is meant. This system of specifying diluted acids is used throughout this paper.
} 
Method C (Applicable to "metaphosphate", superphosphate, and phosphate rock). - Transfer $0.5000 \mathrm{~g}$ of the material to a platinum dish, and add $10 \mathrm{ml}$ of water, $5 \mathrm{ml}$ of hydrofluoric acid, and $20 \mathrm{ml}$ of nitric acid. Digest, and evaporate on the steam bath until only about $5 \mathrm{ml}$ of solution remains. Then add $10 \mathrm{ml}$ of water and $20 \mathrm{ml}$ of nitric acid, and again evaporate until only about $5 \mathrm{ml}$ of solution remains. Add $50 \mathrm{ml}$ of diluted nitric acid $(1+99)$, and digest on the steam bath for 10 minutes. Transfer the solution to a 300-ml Erlenmeyer flask, and proceed with the addition of ammonium citrate, hydrochloric acid, and magnesia mixture as described in 2 .

\section{DETERMINATION OF PHOSPHORIC ANHYDRIDE}

To the solution in the 300-ml Erlenmeyer flask, add $30 \mathrm{~g}$ of ammonium citrate, $10 \mathrm{ml}$ of hydrochloric acid, and $100 \mathrm{ml}$ of magnesia mixture. ${ }^{5}$ Neutralize the solution with ammonium hydroxide, using litmus paper as indicator, and add $3 \mathrm{ml}$ of ammonium hydroxide in excess. Dilute the solution to 225 to $250 \mathrm{ml}$ with water, add a few glass beads, stopper the flask tightly, shake on a shaking machine for about one-half hour, and allow to stand overnight. Filter through a paper of close texture, and wash the flask and paper once with a small quantity of diluted ammonium hydroxide $(1+19)$. Discard the filtrate.

Dissolve any magnesium ammonium phosphate remaining in the flask in about $50 \mathrm{ml}$ of warm diluted hydrochloric acid $(1+4)$, and pour the solution through the paper to dissolve the phosphate that was transferred to the filter, and to separate any insoluble residue that may have remained if method $B$ or $C$ was used for the preparation of the solution. Wash the paper and flask with more of the same acid, and add $0.3 \mathrm{~g}$ of citric acid and $1 \mathrm{ml}$ of magnesia mixture to the solution, which should have a volume of about $100 \mathrm{ml}$. While stirring, add ammonium hydroxide until the solution is alkaline to litmus, and then add $5 \mathrm{ml}$ in excess. Stir occasionally during one-half hour, and allow to stand for 4 hours or overnight.

Collect the precipitate on a 9-cm paper of close texture, wash with cool diluted ammonium hydroxide $(1+19)$, and transfer the paper and precipitate to a weighed platinum or porcelain crucible. Char the paper without flaming, burn off the carbon below $900^{\circ} \mathrm{C}$, and finally ignite to constant weight, preferably in a muffle, at 1,050 to $1,100^{\circ} \mathrm{C}$.

The weight of the magnesium pyrophosphate, $\mathrm{Mg}_{2} \mathrm{P}_{2} \mathrm{O}_{7}$, multiplied by 63.79 and divided by the weight of the sample yields the percentage of $\mathrm{P}_{2} \mathrm{O}_{5}$ in the sample.

Tests have shown that in the analysis of phosphate rock the time of standing in the first precipitation can be reduced to 3 hours and in the second to 2 hours, if the solutions are chilled before shaking or stirring and then allowed to stand in ice water or in a refrigerator at 5 to $10^{\circ}$ C. With small quantities (less than $10 \mathrm{mg}$ of $\mathrm{P}_{2} \mathrm{O}_{5}$ ), the longer time of standing is essential, and even then it is best to chill and shake alternately two or three times. (See footnote $d$ under table 1.)

\footnotetext{
${ }_{5}^{5}$ Prepare the magnesia mixture as follows: Dissolve $400 \mathrm{~g}$ of $\mathrm{MgCl}_{2} \cdot 6 \mathrm{H}_{2} \mathrm{O}$ and $300 \mathrm{~g}$ of ammonium chloride in $1,500 \mathrm{ml}$ of warm water. When solution is complete, add ammonium hydroxide until the solution is alkaline to litmus. Allow to stand for about 1 hour, filter, and add hydrochloric acid to the filtrate until the solution is acid to litmus. If properly prepared, the volume of the solution is almost exactly 2 liters.
} 


\section{RESULTS OBTAINED IN THE USE OF THE METHOD}

The results obtained for phosphoric anhydride in synthetic solutions and in solutions of phosphate rocks and similar materials are shown in tables 1 and 2. The solution of phosphoric acid that was used in adding known amounts of phosphorus in preparing the mixtures designated in table 1 was standardized by the method involving two precipitations with magnesia mixture. ${ }^{6}$ The "other substances present" in table 1 and the "substances added" in table 2 were tested and found to be free from phosphorus.

TABLE 1.-Results obtained for $\mathrm{P}_{2} \mathrm{O}_{5}$ by applying the procedure to solutions of synthetic mixtures

\begin{tabular}{|c|c|c|}
\hline $\begin{array}{c}\mathrm{P}_{2} \mathrm{O}_{5} \text { pres- } \\
\text { ent (stand- } \\
\text { ard solu- } \\
\text { tion of } \\
\mathrm{H}_{3} \mathrm{PO}_{4} \text { ) }\end{array}$ & $\begin{array}{l}\mathrm{P}_{2} \mathrm{O}_{5} \\
\text { found }\end{array}$ & Other substances present \\
\hline $\begin{array}{r}\mathrm{g} \\
0.0783 \\
.0822 \\
.0880 \\
.1068 \\
.0107 \\
.0031 \\
.0031\end{array}$ & $\begin{array}{r}\mathrm{g} \\
.0780 \\
.0821 \\
.0881 \\
.1067 \\
.0106 \\
.0027 \\
\text { d. } 0031\end{array}$ & $\begin{array}{l}0.20 \mathrm{Al}_{2} \mathrm{O}_{3}, 0.20 \mathrm{Fe}_{2} \mathrm{O}_{3}, 0.05 \mathrm{ZnO}, 0.3 \mathrm{CaO}, 0.03 \mathrm{MnO} \text {. } \\
.10 \mathrm{Al}_{2} \mathrm{O}_{3}, .20 \mathrm{Fe}_{2} \mathrm{O}_{3}, .3 \mathrm{CaO} \text {. } \\
.10 \mathrm{Al}_{2} \mathrm{O}_{3}, .20 \mathrm{Fe}_{2} \mathrm{O}_{3}, .3 \mathrm{CaO} . \\
.10 \mathrm{Al}_{2} \mathrm{O}_{3}, .20 \mathrm{Fe}_{2} \mathrm{O}_{3}, .3 \mathrm{CaO} . \\
.10 \mathrm{Al}_{2} \mathrm{O}_{3}, .20 \mathrm{Fe}_{2} \mathrm{O}_{3}, .3 \mathrm{CaO} . \\
.10 \mathrm{Al}_{2} \mathrm{O}_{3}, .20 \mathrm{Fe}_{2} \mathrm{O}_{3}, .3 \mathrm{CaO} . \\
.10 \mathrm{Al}_{2} \mathrm{O}_{3}, .20 \mathrm{Fe}_{2} \mathrm{O}_{3}, .3 \mathrm{CaO} .\end{array}$ \\
\hline
\end{tabular}

a Tests showed that the ignited pyrophosphate contained no significant amounts of $\mathrm{ZnO}$ and $\mathrm{MnO}$.

b A test showed that the ignited pyrophosphate contained approximately $0.1 \mathrm{mg}$ of $\mathrm{Fe}_{2} \mathrm{O}_{3}$.

- A test showed that the ignited pyrophosphate contained less than $0.1 \mathrm{mg}$ of $\mathrm{CaO}$.

d To obtain this result, the solution was chilled at the beginning of the first precipitation, shaken for 1 hour, allowed to stand at 5 to $10^{\circ} \mathrm{C}$ overnight, shaken again for 1 hour, and then allowed to stand 2 or 3 hours before filtering. The ignited pyrophosphate contained no $\mathrm{Al}_{2} \mathrm{O}_{3}$, no $\mathrm{CaO}$, and less than $0.1 \mathrm{mg}$ of $\mathrm{Fe}_{2} \mathrm{O}_{3}$.

\footnotetext{
${ }^{6}$ See J. I. Hoffman and G. E. F. Lundell, BS J. Research 5, 279 (1930) RP200.
} 
TABLE 2.-Results obtained for $\mathrm{P}_{2} \mathrm{O}_{5}$ by applying various methods to phosphate rocks, superphosphate, and other materials

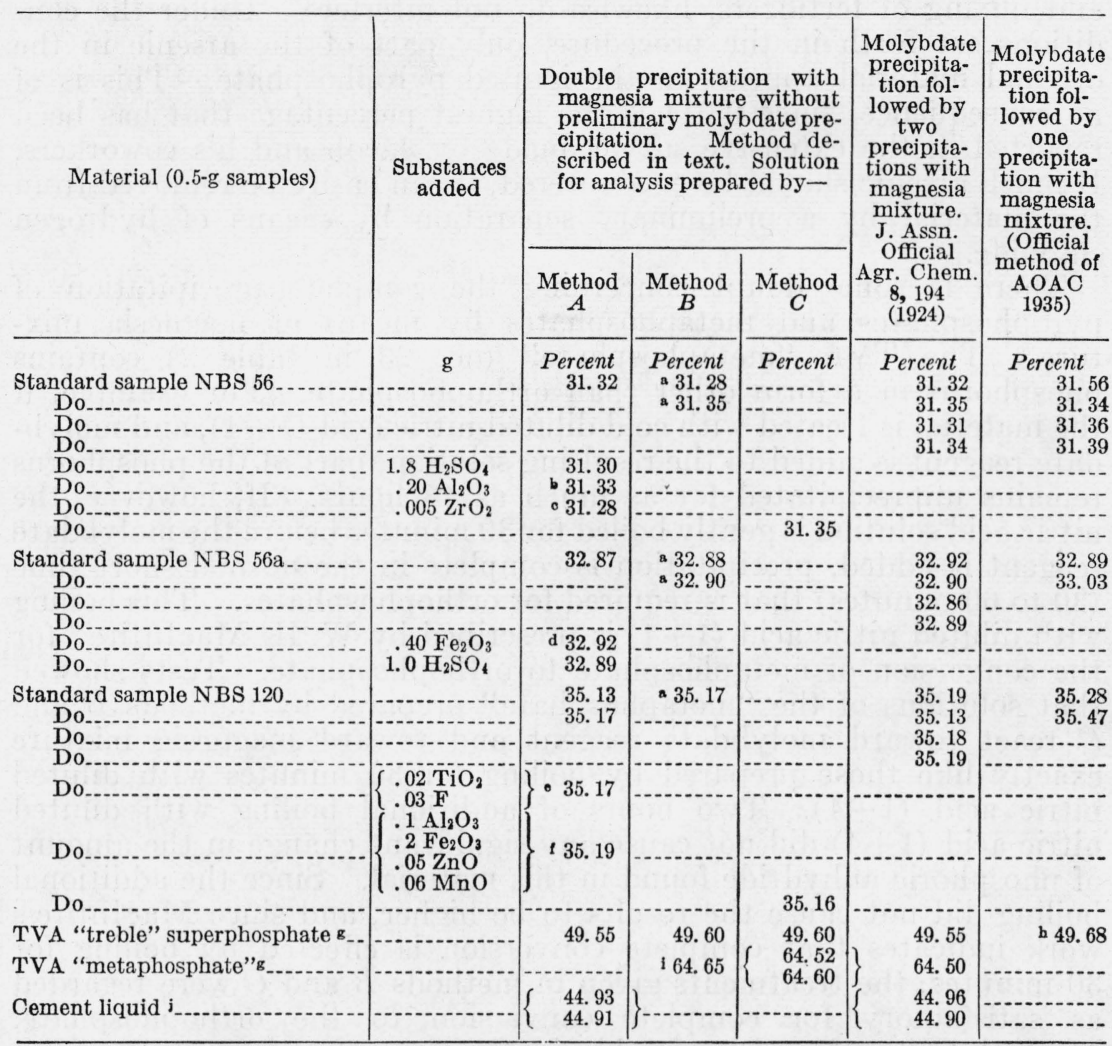

a Tests showed that the ignited pyrophosphates contained no significant amounts of $\mathrm{CaO}_{\text {or }} \mathrm{SiO}_{2}$. The certificate value for $\mathrm{P}_{2} \mathrm{O}_{3}$ in this sample is 31.32 percent.

The ignited pyrophosphate was examined for $\mathrm{Al}_{2} \mathrm{O}_{3}$. No significant amount was found.

c After dissolving the first precipitate of magnesium ammonium phosphate by pouring dilute hydrochloric acid through the filter, the paper was ignited at a low temperature and the residue examined for $\mathrm{ZrO}_{2}$ and $\mathrm{P}_{2} \mathrm{O}_{5}$. A little $\mathrm{ZrO}_{2}$ and about $0.2 \mathrm{mg}$ of $\mathrm{P}_{2} \mathrm{O}_{5}$ were found.

$\mathrm{d}$ The ignited pyrophosphate contained about $0.2 \mathrm{mg}$ of $\mathrm{Fe}_{2} \mathrm{O}_{3}$

- No titanium was found in the ignited pyrophosphate.

'Tests showed that the ignited pyrophosphate contained no significant amounts of $\mathrm{ZnO}$ and $\mathrm{MnO}$

g The samples of these materials were furnished through the courtesy of W. H. MacIntire, chemist, Tennessee Valley Authority, Knoxville, Tenn. These superphosphates and "metaphosphates" are similar to phosphate rocks in composition, excepting that the percentage of $\mathrm{P}_{2} \mathrm{O}_{3}$ is greater. For a discussion of the "metaphosphate" see W. H. MacIntire, L. J. Hardin, and F. D. Oldham, Ind. Eng. Chem. 29, 224 (1937).

h Result obtained volumetrically 2 years ago by W. H. MacIntire.

$i$ The condition of the silica in this material is such that filtration is very slow. Consequently method $C$ for the preparation of the solution is recommended.

$j$ Analysis by I. C. Schoonover. These liquids, used with silicate cements in dentistry, also contain zinc and in some cases aluminum and magnesium. The zinc is now regularly determined in the filtrate obtained from the precipitation with magnesia mixture.

\section{DISCUSSION OF THE METHOD AND ITS APPLICATION}

An inspection of the data shows that very accurate results can be obtained for phosphoric anhydride without the preliminary precipitation with molybdate reagent. During the precipitations with magnesia mixture, the solutions must stand for considerable periods, but not much of the analyst's time is required. Iron, aluminum, titanium, silica, calcium, zinc, manganese, fluorine, and organic matter in the percentages found in phosphate rock ${ }^{7}$ do not interfere.

${ }^{7}$ For the composition of phosphate rock, see K. D. Jacob, W. L. Hill, H. L. Marshall, and D. S. Reynolds, Tech. Bul. 364, U. S. Department of Agriculture, Washington, D. C. (1933). 
Sulphates and nitrates, which might be introduced in the manufacture and mixing of fertilizers, likewise do not interfere. Under the conditions set forth in the procedure, only part of the arsenic in the original material appears in the ignited pyrophosphate. This is of no consequence, since 0.014 is the highest percentage that has been reported in the extensive survey made by Jacob and his coworkers. If much arsenic should be encountered, it can easily be removed from the material by a preliminary separation by means of hydrogen sulphide.

There is some doubt concerning the complete precipitation of pyrophosphates and metaphosphates by means of magnesia mixture. ${ }^{8}$ The TVA "metaphosphate" (no. 23 in table 2) contains phosphorus in a form other than orthophosphate. For example, if the material is treated with cold diluted nitric acid $(1+4)$, and molybdate reagent is added to the resulting solution, part of the phosphorus remains unprecipitated for as much as 48 hours. If, however, the nitric acid solution is gently boiled for 30 minutes before the molybdate reagent is added, precipitation is complete in the normal short time (30 to 60 minutes) that is required for orthophosphates. This boiling with diluted nitric acid $(1+4)$ is prescribed by W. H. MacIntire ${ }^{9}$ for the conversion of metaphosphate to orthophosphate. Tests showed that solutions of the "metaphosphate" prepared by methods $B$ and $C$ react toward molybdate reagent and toward magnesia mixture exactly like those prepared by boiling for 30 minutes with diluted nitric acid $(1+4)$. Two hours of additional boiling with diluted nitric acid $(1+4)$ did not cause any significant change in the amount of phosphoric anhydride found in this material. Since the additional boiling did not cause the results to be higher, and since MacIntire's work indicates that complete conversion is effected by boiling for 30 minutes, the treatments given in methods $B$ and $C$ were regarded as satisfactory for complete conversion to the orthophosphate. Method $C$ was found preferable in the case of the metaphosphate because the use of hydrofluoric acid eliminates the gelatinous silica which would otherwise render filtration very slow.

The use of $30 \mathrm{~g}$ of ammonium citrate is recommended in the procedure. A much smaller quantity will easily prevent the precipitation of iron and aluminum in a solution of a $0.5-\mathrm{g}$ sample of material containing as high as 40 percent of iron oxide or alumina. It was found, however, that these large amounts of iron or aluminum, even though they remain in solution, prevent the complete precipitation of phosphorus by magnesia mixture unless a large excess of ammonium citrate is present.

The method is applicable to phosphate rock, superphosphate, "metaphosphate", and similar materials. Its application in the analysis of liquids used with silicate cements in dentistry has also been demonstrated. (See table 2.)

For routine analyses it is not sufficiently rapid, however, to replace the much used volumetric method in which the ammonium phosphomolybdate is dissolved in a standard solution of sodium hydroxide.

Washington, May 21, 1937.

${ }^{8}$ Th. Wilhelm Fresenius, Introduction to Qualitative Chemical Analysis, translated by C. Ainsworth Mitchell, p. 418, 1921 ed., J. Wiley and Sons, New York, N. Y.

Private communication. 